\title{
Association of clinical events with everolimus exposure in kidney transplant patients receiving reduced cyclosporine
}

Shihab FS, Cibrik D, Chan L, Kim YS, Carmellini M, Walker R, Zibari G, Pattison J, Cornu-Artis C, Wang Z, Tedesco-Silva H Jr. Association of clinical events with everolimus exposure in kidney transplant patients receiving reduced cyclosporine.

Abstract: Background: The association between clinical events and everolimus exposure in patients receiving reduced-exposure calcineurin inhibitor therapy is poorly explored.

Methods: In a pre-planned, descriptive analysis of data from a randomized controlled trial, events were correlated with everolimus trough concentrations in 556 newly transplanted kidney transplant patients receiving everolimus with reduced-exposure cyclosporine (CsA) and steroids. Influence of everolimus exposure on clinical events was stratified according to predefined time-normalized concentrations. Results: The incidence of treated biopsy-proven acute rejection and graft loss at month 12 was highest in patients with everolimus $<3 \mathrm{ng} / \mathrm{mL}$ (36.4\% and $28.6 \%$, respectively, vs. $9.1-15.3 \%$ and $0.9-5.0 \%$ with higher concentration ranges). A higher mortality rate was observed in patients with an everolimus trough concentration $\geq 12 \mathrm{ng} / \mathrm{mL}$ ( $10.0 \%$ vs. $1.7-$ $5.6 \%$ with lower concentration ranges). The lowest rates of renal dysfunction (defined as poor renal function [estimated GFR, serum creatinine] or proteinuria), wound healing events, peripheral edema, new-onset diabetes mellitus, hypercholesterolemia and hypertriglyceridemia were generally observed with everolimus trough concentration in the range $3-8 \mathrm{ng} / \mathrm{mL}$ and $\mathrm{CsA}<100 \mathrm{ng} / \mathrm{mL}$. Proteinuria occurred most frequently in patients with very low or very high everolimus trough concentrations.

Conclusions: These results support an exposure-response relationship between clinical events and everolimus trough concentrations in kidney transplant patients receiving reduced-exposure CsA.

\section{Fuad S. Shihab ${ }^{a}$, Diane Cibrik ${ }^{b}$, Laurence Chan ${ }^{c}$, Yu Seun Kim ${ }^{\text {d, }}$ Mario Carmellini ${ }^{\mathrm{e}}$, Rowan Walker ${ }^{\mathrm{f}}$, Gazi Zibari $^{\mathrm{g}}$, James Pattison ${ }^{\mathrm{h}}$, Catherine Cornu-Artis', Zailong Wang $^{i}$ and Helio Tedesco-Silva Jr ${ }^{j}$}

aDivision of Nephrology, University of Utah School of Medicine, Salt Lake City, UT,

${ }^{b}$ Department of Internal Medicine, University of Michigan, Ann Arbor, MI, 'Health Sciences Center, University of Colorado, Denver, CO, USA, ${ }^{d}$ Yonsei University College of Medicine Severance Hospital, Seoul, Korea,

e Department of Surgery and Bioengineering, University of Siena, Siena, Italy, ${ }^{\mathrm{f}}$ The Royal Melbourne Hospital, Parkville, VIC, Australia, 'Louisiana State Health Sciences Center, Shreveport, LA, USA, 'Guy's and St Thomas's NHS Foundation Trust, London, UK, 'Novartis Pharma AG, Basel, Switzerland and 'Hospital do Rim e Hipertensão, São Paulo, Brazil

Key words: efficacy - everolimus exposure - kidney transplantation therapeutic drug monitoring

Corresponding author: Fuad S. Shihab, MD, Kidney \& Pancreas Transplantation, University of Utah School of Medicine, Nephrology 4R312SOM, 30 N. 1900 E., Salt Lake City, UT 84132, USA.

Tel.: 801585 6709/6700; fax: 801581 4343; e-mail: Fuad.Shihab@hsc.utah.edu

Trial registration: NCT00251004.

Conflicts of interest: The authors disclose the following relevant financial relationships: Fuad Shihab is a scientific advisor for Novartis and has received speaker's honoraria and research funding from Novartis; Diane Cibrik is a scientific advisor for Novartis, Pfizer, and Tolera Therapeutics; Laurence Chan is a scientific advisor for Novartis; Yu Seun Kim has received grants from Astellas, Novartis, Wyeth, Pfizer, and Roche; Mario Carmellini has acted as a scientific adviser for Astellas; Rowan Walker has previously served or is currently serving as a consultant for Novartis, Janssen-Cilag, Roche, and Wyeth; Gazi Zibari has no conflicts of interest to declare; James 


\author{
Pattison has received honoraria from Novartis \\ and Bristol-Myers Squibb; Helio Tedesco Silva \\ Jr has received grant/research support from \\ Novartis, Astellas, Janssen-Cilag, Bristol- \\ Myers Squibb, and Wyeth, payment for \\ scientific advice from Novartis and honoraria \\ from Novartis, Astellas, Janssen-Cilag, Bristol- \\ Myers Squibb, and Wyeth; Catherine Cornu- \\ Artis and Zailong Wang are employees of \\ Novartis. \\ Accepted for publication 9 October 2012
}

The mammalian target of rapamycin (mTOR) inhibitors exert their immunosuppressive effect by blocking growth factor-driven T-cell proliferation $(1,2)$, complementing the early inhibition of IL-2 gene transcription by calcineurin inhibitors (CNIs). This synergism between mTOR inhibitors and CNIs permits CNI dose/exposure reduction (2) and a series of studies has confirmed that use of an mTOR inhibitor with reduced-exposure CNI regimen incurs no loss of efficacy following kidney transplantation (3-8).

Analyses of pharmacokinetic data from earlier studies in which kidney transplant patients received a fixed dose of the mTOR inhibitor everolimus with standard-exposure cyclosporine (CsA) showed a clear association between the everolimus trough concentration and incidence of biopsy-proven acute rejection (BPAR) $(9,10)$. An increased risk of BPAR was observed for everolimus trough concentration below $3 \mathrm{ng} / \mathrm{mL}(9,10)$. In contrast, everolimus trough concentration $>3 \mathrm{ng} / \mathrm{mL}$ prevented more than $80 \%$ of BPAR episodes (10).

Similar analyses of the association between clinical events and everolimus exposure when used in combination with reduced CNI dose/exposure are rare (11). The A2309 study was a 24-month trial in which 833 de novo kidney transplant patients were randomized to everolimus trough concentrations between 3 and $8 \mathrm{ng} / \mathrm{mL}$ or between 6 and $12 \mathrm{ng} /$ $\mathrm{mL}$ with reduced CsA exposure or to standard CsA with mycophenolic acid (MPA) (5). A pre-planned, descriptive analysis supported by post hoc exploratory analyses was undertaken to correlate efficacy, renal dysfunction, and safety events with everolimus and CsA concentrations and the results are reported here.

\section{Materials and methods}

Study design and conduct

The study methodology has been described in detail previously (5) and additional information is shown in SDC. Briefly, in a 24-month, multicenter, parallel-group, international, open-label trial, adult recipients of a primary, de novo kidney transplant were randomized to one of three treatment arms: (i) everolimus $0.75 \mathrm{mg}$ b.i.d. targeting a trough concentration of 3-8 $\mathrm{ng} / \mathrm{mL}$ with reduced CsA (ii) everolimus $1.5 \mathrm{mg}$ b.i.d. targeting a trough concentration of 6-12 ng/mL with reduced CsA or (iii) MPA as enteric-coated mycophenolate sodium (myfortic $^{\circledR}$, Novartis Pharma AG, Basel, Switzerland) $720 \mathrm{mg}$ b.i.d. with standard CsA. Only patients randomized to receive everolimus and reduced CsA were included in the current analysis.

The study was conducted in accordance with the Declaration of Helsinki following approval from the institutional review board at each center and written informed consent was obtained from all the patients. The study started in October 2005 with the last patient visit in August 2009.

\section{Immunosuppression regimens}

Reduced CsA exposure targeted a CsA trough concentration of $100-200 \mathrm{ng} / \mathrm{mL}$ starting at day 5 visit; $75-150 \mathrm{ng} / \mathrm{mL}$ starting at the month 2 visit; $50-100 \mathrm{ng} / \mathrm{mL}$ starting at the month 4 visit; and 25 $-50 \mathrm{ng} / \mathrm{mL}$ starting at the month 6 visit and maintained thereafter. All patients received basiliximab induction and corticosteroids were administered according to local practice and patients were low to moderate immunological risk.

\section{Primary endpoint}

The primary endpoint was efficacy failure at month 12 defined as treated BPAR (tBPAR), graft loss, death, or loss to follow-up.

\section{Definitions}

Poor renal function or proteinuria at months 12 and 24 was defined as: (i) a low estimated glomerular filtration rate (eGFR) defined as eGFR 
$<30 \mathrm{~mL} / \mathrm{min} / 1.73 \mathrm{~m}^{2}$ (MDRD formula (12)) (ii) a decreased eGFR defined as a decrease in renal function by $>30 \%$ as compared to month 1 as assessed by either eGFR (MDRD and Nankivell (13) equations) or creatinine clearance $(\mathrm{CrCl})$ (Cockcroft-Gault (14) formula) (iii) a high serum creatinine defined as $\geq 200 \mu \mathrm{M}(2.28 \mathrm{mg} / \mathrm{dL})$ after month 1 and (iv) proteinuria defined as urinary protein:creatinine ratio $\geq 300 \mathrm{mg} / \mathrm{g}(30 \mathrm{mg} / \mathrm{mmol})$ after month 1.

New-onset diabetes mellitus (NODM) (i.e., occurring in patients who were non-diabetics at the time of transplant) was defined as (i) diabetes reported as an adverse event $>14 \mathrm{~d}$ after the date of transplantation or (ii) a random glucose $\geq 11 \mathrm{mM} \quad(200 \mathrm{mg} / \mathrm{dL}) \quad 14 \mathrm{~d}$ after transplant (excluding elevated glucose levels that resolved within 14 d) or (iii) diabetes recorded as the reason for diabetic medication given $14 \mathrm{~d}$ after transplantation and lasting for $14 \mathrm{~d}$ or more. Hypercholesterolemia was defined as total cholesterol $\geq 6.2 \mathrm{mM}(239 \mathrm{mg} / \mathrm{dL})$, hypertriglyceridemia as triglycerides $\geq 5.6 \mathrm{mM}(496 \mathrm{mg} / \mathrm{dL})$, and low testosterone in male patients as testosterone $<10 \mathrm{nM}$ if age $<50 \mathrm{yr}$ or $<7 \mathrm{nM}$ if age $\geq 50 \mathrm{yr}$.

\section{Statistical methods}

No formal testing of differences between patient subpopulations was undertaken. Such testing was not considered statistically valid because (i) patients were randomized either to the everolimus 3-8 or $6-12 \mathrm{ng} / \mathrm{mL}$ treatment groups and not to the drug exposure subpopulations used in this analysis and (ii) different numbers of patients were in the trough concentration ranges.

All efficacy events were included in the analysis as there were too few on-treatment efficacy events to be considered for analysis alone. Renal and safety events were included only in patients remaining on treatment. Efficacy events (tBPAR, graft loss and death) and renal events were assessed at 12 and 24 months. Safety events (adverse events, selected hematological events, and lipid and hormone changes) were selected for analysis if they occurred with an incidence $\geq 5 \%$ in the everolimus group or were more frequent in the everolimus treatment group than in the MPA cohort ( $p$ value $\leq 0.1$, chi-square test). Few safety events occurred from month 12 to month 24, preventing a meaningful interpretation of data, so safety analyses are restricted up to month 12 .

Data are based on centrally measured time-normalized mean trough concentrations for everolimus and CsA. Time-normalized mean trough concentrations were calculated as $\Sigma \mathrm{A}_{i} /\left(\mathrm{D}_{k}-\mathrm{D}_{0}\right)$ where $\mathrm{A}_{i}$ is the trapezoid area $(1 / 2)\left[\left(\mathrm{C}_{i-1}+\mathrm{C}_{i}\right)^{\text {* }}\right.$ $\left(\mathrm{D}_{i}-\mathrm{D}_{i-1}\right)$ ] under the concentrations $\mathrm{C}_{i-1}$ and $\mathrm{C}_{i}$, $\mathrm{D}_{i}$ is the blood sampling day for $\mathrm{C}_{i}, i=1, \ldots, k$. $\mathrm{D}_{0}=7$ or the first trough concentration examination date when a trough was obtained after day 7 . Concentrations below the lower limit of quantification $(0.4 \mathrm{ng} / \mathrm{mL})$ were set to $0.2 \mathrm{ng} / \mathrm{mL}$. Data were pooled for both everolimus treatment groups. Time-normalized mean everolimus trough concentrations and time-normalized mean CsA trough concentrations were calculated up to the occurrence of an event or for patients without event, the last on-treatment value and for change in eGFR from month 1 to month 12 or to the last on-treatment sampling date.

The influence of everolimus or CsA exposure on efficacy, renal, and safety events was assessed by dividing the time-normalized mean trough concentrations into predefined ranges $(<3,3-6,6-8,8-12$, and $\geq 12 \mathrm{ng} / \mathrm{mL}$ for everolimus and $<50,50-100$, $100-200$, and $\geq 200 \mathrm{ng} / \mathrm{mL}$ for CsA). To assess the influence of everolimus trough concentrations on efficacy and renal events, median-effect analyses (15) were performed. Post hoc Cox proportional hazard regression modeling was used to estimate the probability of tBPAR and high urinary protein:creatinine ratio $(\geq 300 \mathrm{mg} / \mathrm{g}$ [30 $\mathrm{mg} / \mathrm{mmol}])$ at specified combinations of timenormalized everolimus and CsA trough concentrations, i.e., the predicted incidence of tBPAR and high urinary protein:creatinine ratio was estimated for specific everolimus concentrations $(3,6,8,10$, and $12 \mathrm{ng} / \mathrm{mL}$ ) and CsA concentrations $(50,100$, 150 and $200 \mathrm{ng} / \mathrm{mL}$ ). The linear regression model was applied to evaluate the predicted change in eGFR from month 1 to month 12, using the same specified values of everolimus and CsA concentrations as for tBPAR. The last observation carry forward (LOCF) method was used for missing eGFR values at month 1 or month 12 . The interaction between everolimus and CsA trough concentration was investigated in these regression models.

Analyses of the relationship between everolimus exposure and efficacy or renal events were performed on the pharmacokinetic efficacy population, comprising all intent-to-treat patients (i.e., all randomized patients) who provided any everolimus or CsA trough concentration measurement. Analyses of everolimus exposure and safety events were performed on all patients in the safety population (i.e., patients who received at least one dose of study drug and provided a post-baseline safety assessment) who provided any everolimus or CsA trough concentration measurement after randomization. As only those patients with exposure data available at the time of the event or who were 
event-free at the specified time point were included, the total number of patients available for analysis varies among events. Time-normalized values of CsA concentration were calculated up to an event or up to the last on-treatment value for event-free patients. As the occurrence of acute rejection is expected to be concentrated in the early post-transplant period before protocol-mandated CsA exposure reductions occurred, CsA exposure values will be heavily skewed upward in patients who experienced tBPAR. To account for this, an additional analysis was performed that uses data up to day 45 (the end of the month 1 visit window) prior to CsA exposure reduction.

\section{Results}

\section{Patient population}

Five hundred fifty-six patients were randomized to receive everolimus $(277$ at $1.5 \mathrm{mg} / \mathrm{d}, 279$ at $3.0 \mathrm{mg} / \mathrm{d}$ ). The mean age was $45.5 \mathrm{yr}$ and $66.2 \%$ of patients were male with no marked differences in demographics or baseline characteristics between treatment groups (Table 1). At months 12 and 24 , respectively, $490(88.1 \%)$ and 470 $(84.5 \%)$ everolimus-treated patients remained in the study; $354(63.7 \%)$ and $328(59.0 \%)$ remained on the study medication.

Table 1. Demographics and patient characteristics by treatment group

\begin{tabular}{|c|c|c|c|}
\hline & $\begin{array}{l}\text { Everolimus } \\
1.5 \mathrm{mg} / \mathrm{d} \\
\mathrm{N}=277\end{array}$ & $\begin{array}{l}\text { Everolimus } \\
3.0 \mathrm{mg} / \mathrm{d} \\
\mathrm{N}=279\end{array}$ & $\begin{array}{l}\text { All everolimus } \\
\text { patients } \\
\mathrm{N}=556\end{array}$ \\
\hline Age, yr & $45.7(12.7)$ & $45.3(13.4)$ & $45.5(13.0)$ \\
\hline Male, \% & $177(63.9)$ & $191(68.5)$ & $368(66.2)$ \\
\hline White, \% & $193(69.7)$ & $180(64.5)$ & $373(67.1)$ \\
\hline \multicolumn{4}{|c|}{ Cause of end-stage renal disease, $\mathrm{n}(\%)$} \\
\hline $\begin{array}{l}\text { Hypertension/ } \\
\text { nephrosclerosis }\end{array}$ & $50(18.1)$ & $56(20.1)$ & $106(19.1)$ \\
\hline Glomerular disease & $44(15.9)$ & $55(19.7)$ & $99(17.8)$ \\
\hline Diabetes mellitus & $39(14.1)$ & $29(10.4)$ & $68(12.2)$ \\
\hline Polycystic disease & $36(13.0)$ & $29(10.4)$ & $65(11.7)$ \\
\hline Unknown & $33(11.9)$ & $37(13.3)$ & $70(12.6)$ \\
\hline Other & $75(27.1)$ & $73(26.2)$ & $148(26.6)$ \\
\hline HLA mismatches & $3.5(1.54)$ & $3.3(1.59)$ & $3.4(1.57)$ \\
\hline $\begin{array}{l}\text { PRA (peak evaluation) } \\
\geq 20 \%, \mathrm{n}(\%)\end{array}$ & $17(6.1)$ & $13(4.7)$ & $30(5.4)$ \\
\hline Donor age, yr & $41.4(13.9)$ & $41.1(13.0)$ & $41.2(13.4)$ \\
\hline $\begin{array}{l}\text { Deceased donor (heart } \\
\text { beating), }(\mathrm{n} \%)\end{array}$ & $128(46.2)$ & $126(45.2)$ & $254(45.7)$ \\
\hline \multicolumn{4}{|c|}{ CMV serology status, n (\%) } \\
\hline $\mathrm{D}+/ \mathrm{R}+$ & $140(50.5)$ & $139(49.8)$ & $279(50.2)$ \\
\hline $\mathrm{D}+/ \mathrm{R}_{-}$ & $30(10.8)$ & $28(10.0)$ & $58(10.4)$ \\
\hline $\mathrm{D}-/ \mathrm{R}+$ & $36(13.0)$ & $44(15.8)$ & $80(14.4)$ \\
\hline $\mathrm{D}-/ \mathrm{R}-$ & $62(22.4)$ & $53(19.0)$ & $115(20.7)$ \\
\hline
\end{tabular}

Continuous variables are shown as mean (SD).

\section{Efficacy events}

Among the patients receiving everolimus, tBPAR had occurred in 86 patients $(15.5 \%)$, graft loss in 26 patients $(4.7 \%)$, and death in 17 patients $(3.1 \%)$ by month 12 . At month 24 , the corresponding numbers were $97(17.4 \%), 33(5.9 \%)$, and 19 $(3.4 \%)$. The incidence of tBPAR was markedly higher in patients with an everolimus trough concentration $<3 \mathrm{ng} / \mathrm{mL}(36.4 \%$ at month $12,47.6 \%$ at month 24) but no difference in the incidence of tBPAR was observed above $3 \mathrm{ng} / \mathrm{mL}$ except at everolimus trough concentrations $\geq 12 \mathrm{ng} / \mathrm{mL}$ where the incidence of tBPAR was lower $(9.1 \%$ at month 12, 10.0\% at month 24) (Fig. 1A, Table 2). Kaplan-Meier analysis of the proportion of patients free from tBPAR in the $<3,3-6,6-8,8-$ 12 , and $\geq 12 \mathrm{ng} / \mathrm{mL}$ groups were $55.9 \%, 85.2 \%$, $84.0 \%, 86.2 \%$, and $89.7 \%$, respectively, at month 12 and $39.9 \%, 83.2 \%, 81.8 \%, 85.3 \%$, and $89.7 \%$ at month 24 . Fig. $2 \mathrm{~A}$ shows a three-dimensional representation of the estimated probability of tBPAR at month 1 at specified combinations of time-normalized everolimus and CsA trough concentration based on data up to day 45 (i.e., the last day of the month 1 study window prior to CsA dose reduction) from the Cox model. Patients with everolimus concentrations below $3 \mathrm{ng} / \mathrm{mL}$ at month 1 showed higher incidences of tBPAR, which were reduced with increasing concentrations of CsA. In contrast, in patients with everolimus concentrations $\geq 8 \mathrm{ng} / \mathrm{mL}$ at month 1 , the incidence of tBPAR was not strongly influenced by CsA concentrations. Although the predicted probabilities in Fig. 2A indicate visually the exposureresponse relationship between the incidence of tBPAR, everolimus concentration and CsA concentration, this could not be demonstrated statistically in the current analysis. The effect of everolimus trough concentrations, CsA trough concentrations, and their interaction on the incidence of tBPAR was statistically non-significant $(\mathrm{p}=0.259,0.295$ and 0.176 , respectively). However, the study was not powered for this analysis and the number of included events was small because of the limited time frame of $45 \mathrm{~d}$, which was selected because CsA concentrations were expected to be constant during this period as per the study design.

The incidence of graft loss at months 12 and 24 was similar within the everolimus range of 3-12 ng/mL (Table 2), but below $3 \mathrm{ng} / \mathrm{mL}$, the incidence of graft loss greatly increased $(28.6 \%$ at month 12, 42.1\% at month 24) (Fig. 1B). Eight graft losses in patients with everolimus trough concentrations $<3 \mathrm{ng} / \mathrm{mL}$ by month 24 were due to 

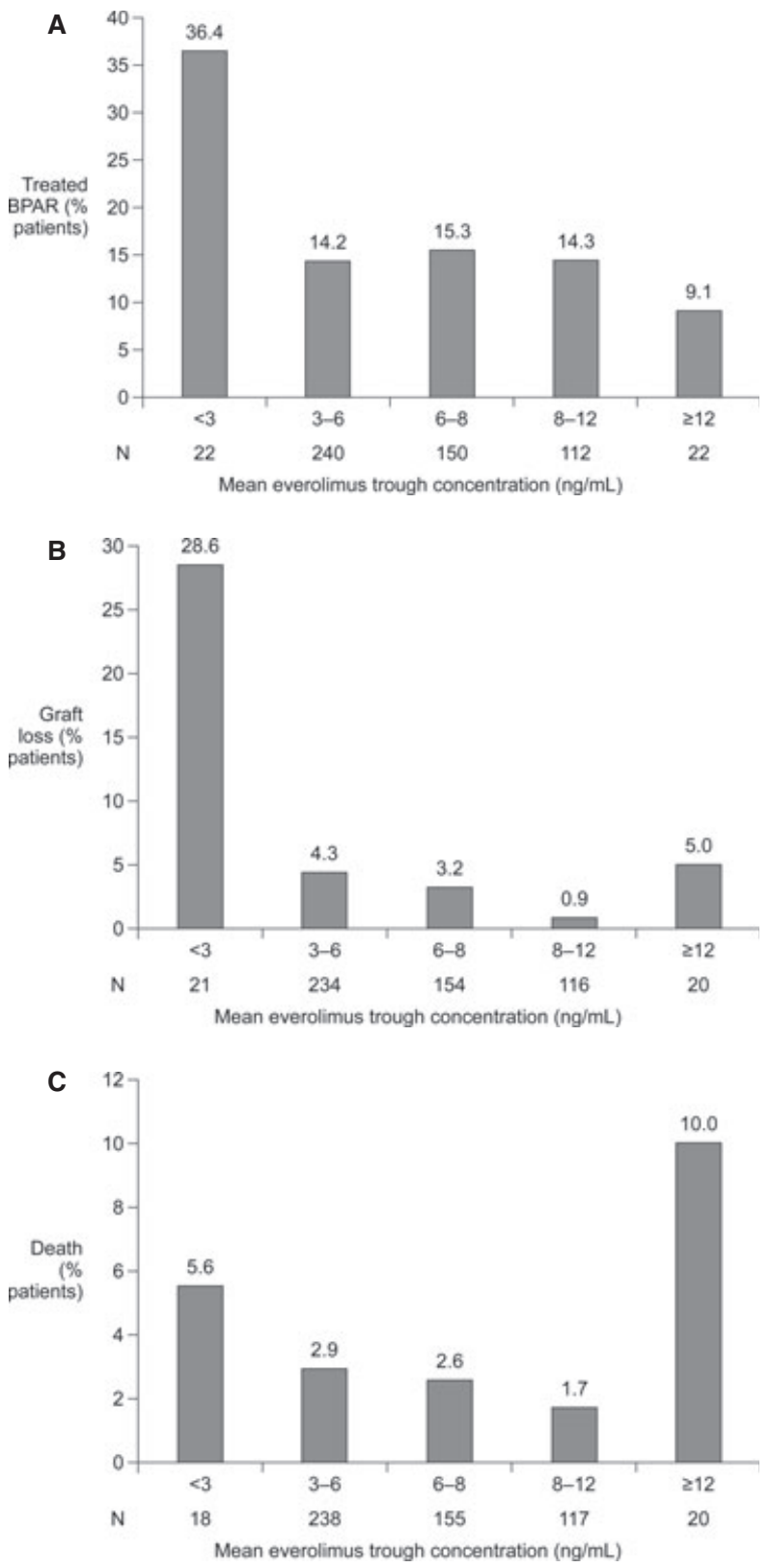

Fig. 1. Incidence of (A) treated biopsy-proven acute rejection (BPAR) (B) graft loss (C) death according to predefined range of mean time-normalized everolimus trough concentration at month 12 post-transplant (pharmacokinetic efficacy population).

acute vascular rejection (two), chronic rejection (three including one presumed), renal artery thrombosis (two) and non-compliance (one). A single graft loss occurred at an everolimus trough concentration $\geq 12 \mathrm{ng} / \mathrm{mL}$ due to acute rejection. A similar pattern was observed for Kaplan-Meier estimates of the proportion of patients free from graft loss at month $12(65.8 \%, 95.5 \%, 96.6 \%$, $99.2 \%$, and $94.7 \%$ in the $<3,3-6,6-8,8-12$ and $\geq 12 \mathrm{ng} / \mathrm{mL}$ groups, respectively) and month 24 $(49.3 \%, 94.5 \%, 95.9 \%, 97.5 \%$, and $94.7 \%$, respectively). Mortality was similar across the everolimus exposure ranges except a higher incidence of mortality was observed in patients with a trough concentration $\geq 12 \mathrm{ng} / \mathrm{mL}$ but the number of events in this range was small (Fig. 1C, Table 2). The two deaths that occurred at an everolimus trough concentration $\geq 12 \mathrm{ng} / \mathrm{mL}$ were caused by acute myocardial infarction and sepsis. The only death in the lowest everolimus range $(<3 \mathrm{ng} / \mathrm{mL})$ was the result of sepsis.

Exploratory exposure-event analyses of everolimus trough concentrations vs. efficacy failure events showed a significant inverse relationship between everolimus exposure at months 12 and 24 and the incidence of graft loss (median-effect logistic regression for combined everolimus groups: month $12, \mathrm{p}=0.007$; month $24, \mathrm{p}=0.004$ ). This trend was mainly driven by a higher incidence of graft loss below an average everolimus trough concentration of $4 \mathrm{ng} / \mathrm{mL}$. No clear relationship was observed between the everolimus trough concentration and TBPAR at month 12 (the analysis was not performed for tBPAR at month 24) or for death at months 12 and 24, although the number of events was low.

\section{Renal events}

Regardless of whether renal function was assessed by eGFR, $\mathrm{CrCl}$, or serum creatinine, more patients had poor renal function at months 12 and 24 when the everolimus exposure was $<3 \mathrm{ng} / \mathrm{mL}$ (Table S1). In contrast, proteinuria defined as $>300 \mathrm{mg}$ protein per gram of creatinine was more frequent in patients either under-exposed $(<3 \mathrm{ng} / \mathrm{mL})$ or overexposed $(\geq 12 \mathrm{ng} / \mathrm{mL})$ to everolimus (SCD, Table 1). The numbers of patients with nephroticrange proteinuria $(\geq 3000 \mathrm{mg} / \mathrm{g}[339 \mathrm{mg} / \mathrm{mmol}])$ at month $12(\mathrm{n}=8)$ and month $24(\mathrm{n}=7)$ were too low to permit a meaningful analysis by everolimus exposure. A significant correlation was observed between everolimus trough concentrations and the incidence of proteinuria (higher trough level leading to a higher rate of events) at months 12 and $24(\mathrm{p}=0.004$ and $\mathrm{p}=0.010$ from logistic regression, respectively) but no correlation was observed for other definitions of renal dysfunction.

In general, as CsA concentrations increased, more patients had poor renal function measured by either low eGFR, decreased eGFR, decreased $\mathrm{CrCl}$, or high serum creatinine level (SDC, Table 1). Poor renal function was observed in a higher proportion of patients when CsA concentrations were above $100 \mathrm{ng} / \mathrm{mL}$ regardless of everolimus concentrations up to $12 \mathrm{ng} / \mathrm{mL}$. A few patients with very low everolimus concentrations 
Shihab et al.

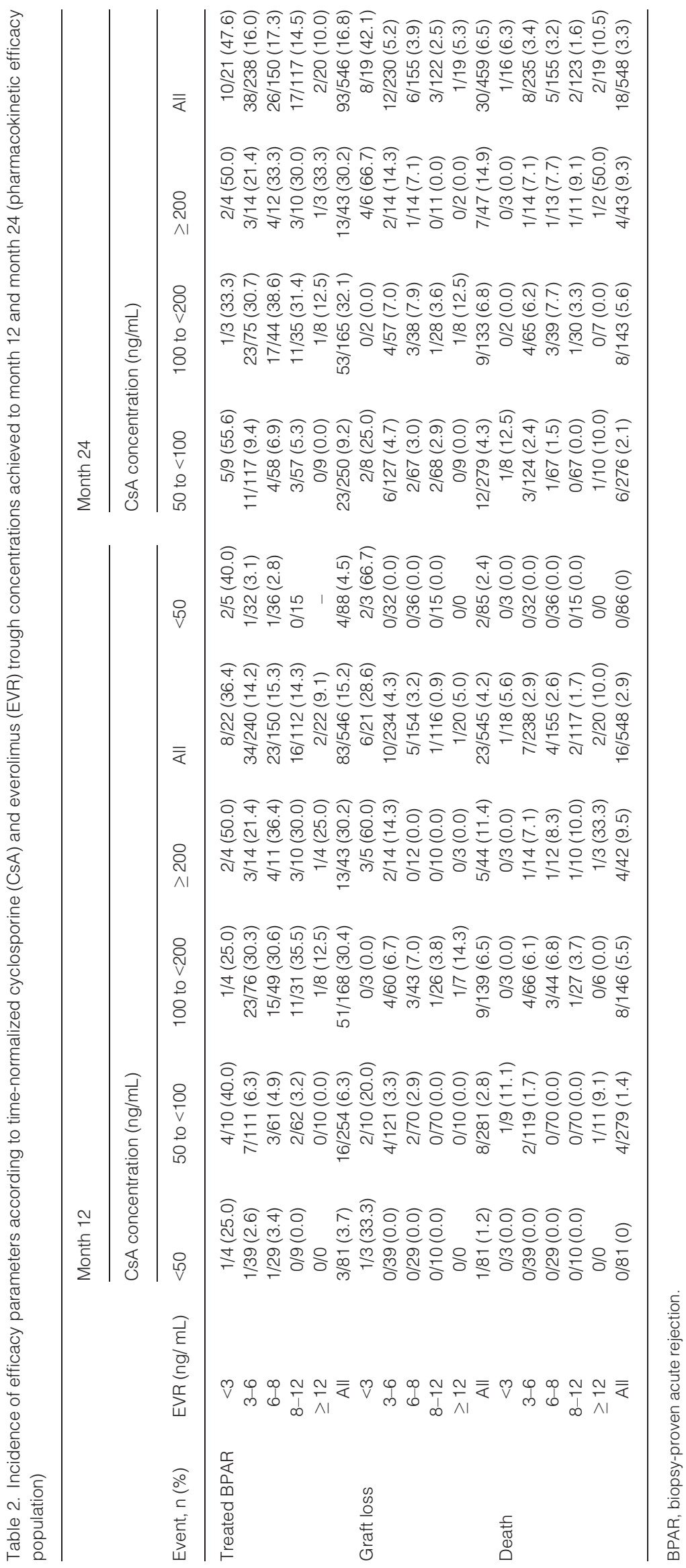


Fig. 2. (A) Estimated probability of treated biopsy-proven acute rejection (tBPAR) at month 1 from Cox proportional hazards model based on data to day 45 (pharmacokinetic efficacy population) (B) the negative change in estimated glomerular filtration rate (eGFR) (MDRD) from month 1 to month 12 at specified combinations of time-normalized everolimus and cyclosporine (CsA) trough concentration from the linear regression model (pharmacokinetic efficacy population - 12-month ontreatment analysis) (C) estimated probability of high urinary protein: creatinine ratio ( $\geq 300 \mathrm{mg} / \mathrm{g}$ after month 1) from Cox proportional hazards model at specified combinations of time-normalized everolimus and CsA trough concentration (pharmacokinetic efficacy population - 12-month ontreatment analysis). All graphs showed predicted values at specified combinations of time-normalized everolimus trough concentration $(3,6$, 8,10 and $12 \mathrm{ng} / \mathrm{mL}$ ) and CsA trough concentration $(50,100,150$ and $200 \mathrm{ng} /$ $\mathrm{mL}$ ) in the pharmacokinetic efficacy population. For example, in Fig. 2A, a patient with time-normalized everolimus trough concentration of $8 \mathrm{ng} / \mathrm{mL}$ and time-normalized everolimus trough concentration of $100 \mathrm{ng} / \mathrm{mL}$ would have a $4.0 \%$ predicted probability of tBPAR.
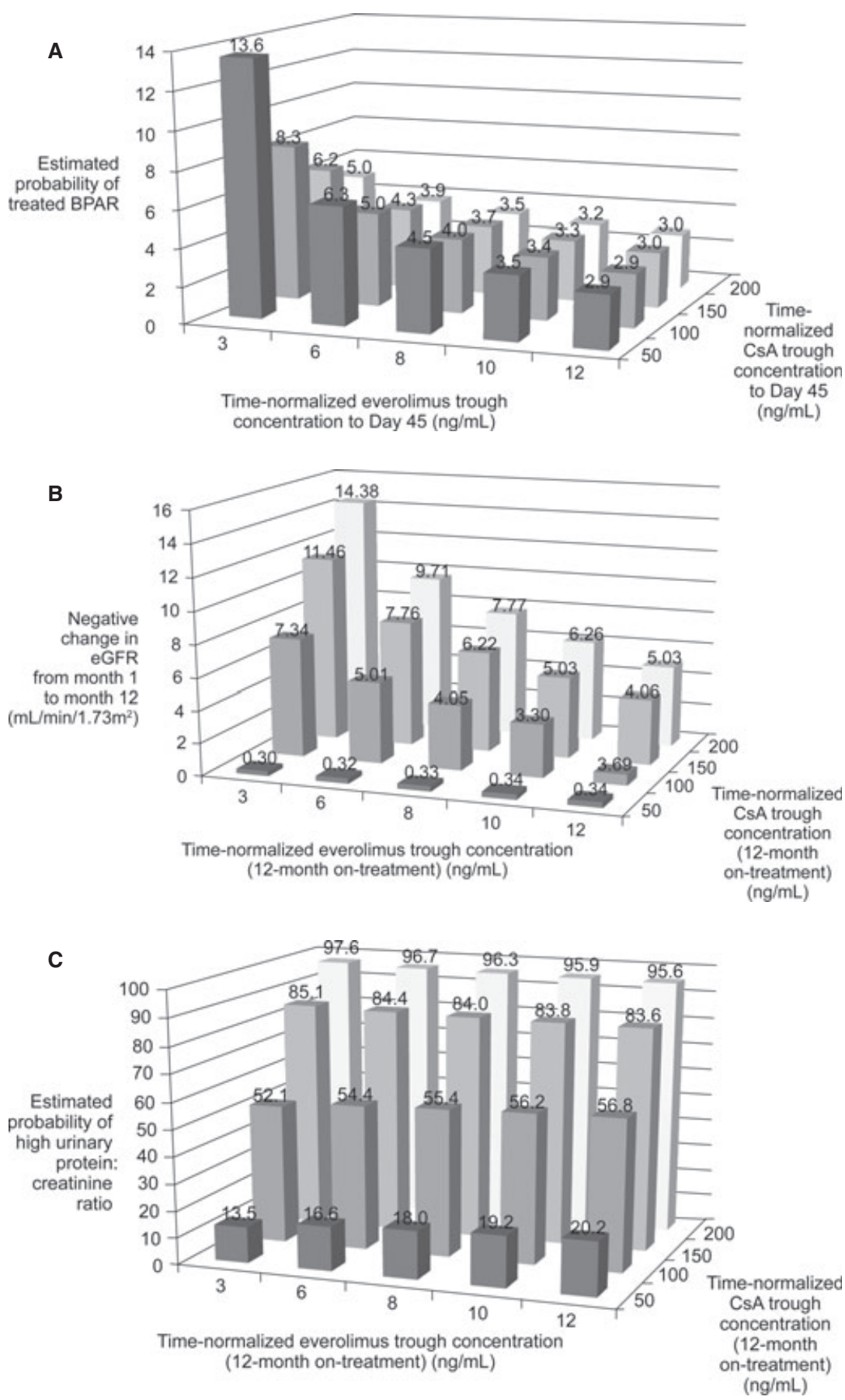

$(<3 \mathrm{ng} / \mathrm{mL})$ and high CsA concentrations had worse renal function. Of note, many categories had very few patients in the denominator making interpretation of the results difficult. In addition, more patients with high everolimus and CsA concentrations had proteinuria (everolimus concentrations $\geq 12 \mathrm{ng} / \mathrm{mL}$ with CsA concentrations $>100 \mathrm{ng} /$ $\mathrm{mL}$ ) (SDC, Table 1). Fig. 2B represents a threedimensional representation of the negative change in eGFR from month 1 to month 12 at specified combinations of time-normalized everolimus and
CsA trough concentrations from the linear regression model. Increasing concentrations of CsA were significantly associated with a substantially greater decline in eGFR $(p=0.077)$. In contrast, higher everolimus concentrations did not show a significant association with the change in eGFR $(\mathrm{p}=0.351)$. At low CsA concentrations $(50 \mathrm{ng} /$ $\mathrm{mL}$ ), a negligible change in eGFR was observed over the first year post-transplant regardless of the everolimus concentration. No statistically significant everolimus and CsA trough concentration 
interaction $(\mathrm{p}=0.288)$ contributed to the change in eGFR. The estimated probability of high urinary protein:creatinine at specified combinations of time-normalized everolimus and CsA trough concentrations from the Cox model, as depicted in Fig. 2C, showed no significant association with everolimus exposure $(\mathrm{p}=0.751)$, but a clear effect could be attributed to increasing CsA exposure $(\mathrm{p}<0.001)$. No significant interaction between everolimus and CsA on proteinuria was observed $(\mathrm{p}=0.335)$.

\section{Safety events}

Safety events that met the criteria for analysis (i.e., incidence $\geq 5 \%$ of patients in the everolimus groups or higher incidence with everolimus than MPA) were wound healing events, peripheral edema, stomatitis/oral ulcers, NODM, hypercholesterolemia, hypertriglyceridemia, and low testosterone in male subjescts. The lowest rates of wound healing events, peripheral edema, NODM, hypercholesterolemia and hypertriglyceridemia were generally observed with everolimus trough concentration in the range $3-8 \mathrm{ng} / \mathrm{mL}$ and CsA $<100 \mathrm{ng} / \mathrm{mL}$ (Table 3). When data from all patients were analyzed, regardless of CsA exposure, the incidence of wound healing events and peripheral edema was lowest when everolimus concentrations were in the range $3-8 \mathrm{ng} / \mathrm{mL}$ (Table 3). No clear correlation was observed between everolimus exposure on stomatitis/oral ulcers or NODM. Hypercholesterolemia and hypertriglyceridemia were frequent events across all everolimus ranges (Table 3). Low testosterone levels did not show any association with everolimus exposure. In general, the incidence of wound healing events, peripheral edema, stomatitis/oral ulcers, NODM, and lipid disorders increased as CsA exposure increased over most everolimus ranges. The highest rates of hypercholesterolemia and hyperlipidemia were observed in patients with high exposure to both CsA and everolimus. No trend was observed for low testosterone levels.

\section{Discussion}

These results support an exposure-response relationship between efficacy and safety and everolimus trough concentration within the range $3-12 \mathrm{ng} / \mathrm{mL}$ in low-to-moderate immunological risk kidney transplant patients. Increasing everolimus exposure above $3 \mathrm{ng} / \mathrm{mL}$ was associated with some additional benefit in reducing the risk of tBPAR. An inverse relationship was observed between everolimus exposure and graft loss at months 12 and 24, with a higher graft loss rate at everolimus trough concentrations below $4 \mathrm{ng} / \mathrm{mL}$ but as the absolute number of events was low, particularly at higher everolimus concentrations, this finding should be interpreted cautiously.

The decrease in eGFR over the first year posttransplant was driven by rising CsA concentration but not by increasing everolimus concentration. At low CsA exposure $(50 \mathrm{ng} / \mathrm{mL})$, eGFR results were excellent regardless of exposure to everolimus (Fig. 2B). A previous analysis in kidney transplant patients has observed only a minor effect of everolimus on serum creatinine in patients receiving standard-exposure CsA (10). The lowest rate of proteinuria was observed in patients with everolimus trough concentration in the range $3-8 \mathrm{ng} / \mathrm{mL}$.

Wound healing events and peripheral edema occurred less frequently in the everolimus exposure range $3-8 \mathrm{ng} / \mathrm{mL}$ than at higher concentrations. Although no consistent correlation between everolimus exposure and NODM was apparent, the high incidence of NODM in patients with mean everolimus concentration $\geq 12 \mathrm{ng} / \mathrm{mL}$ in the presence of CsA concentration $\geq 200 \mathrm{ng} / \mathrm{mL}$ was noteworthy although absolute numbers were small (4/6 patients). Hypercholesterolemia and hypertriglyceridemia were most frequent in patients with CsA trough concentration $\geq 100 \mathrm{ng} / \mathrm{mL}$ and everolimus trough concentration $>8 \mathrm{ng} / \mathrm{mL}$. In summary, an increased risk of certain adverse events was observed with everolimus trough concentrations above $8 \mathrm{ng} / \mathrm{mL}$, and particularly above $12 \mathrm{ng} / \mathrm{mL}$. This is consistent with findings from a recent study of 285 de novo kidney transplant patients randomized to everolimus $3-8$ or $8-12 \mathrm{ng} / \mathrm{mL}$, in which a higher rate of discontinuations due to adverse events occurred in the 8-12 ng/mL arm (16).

Several limitations of the current report need to be considered. Although this study was a largely pre-planned (only the Cox modeling of everolimus and CsA exposure correlations with efficacy and safety events was performed post hoc) analysis of a randomized trial, it is of descriptive nature; statistical comparisons were not valid due to potential bias imposed by the different number of patients in each subpopulation. In addition, only a few patients had either very high or very low everolimus trough concentrations. For example, in the highest everolimus exposure group $(\geq 12 \mathrm{ng} / \mathrm{mL})$, the rate of tBPAR $(9.1 \%$ at month 12$)$ was lower than in any other group, but only 22 patients were in this cohort. Also, graft failure and death occurred rarely, so the results become less reliable. 
Table 3. Incidence of adverse events according to time-normalized cyclosporine (CsA) and everolimus mean trough concentration achieved to month 12, n (\%) (pharmacokinetic safety population)

\begin{tabular}{|c|c|c|c|c|c|c|}
\hline \multirow[b]{3}{*}{ Event, $n(\%)$} & \multirow{3}{*}{$\begin{array}{l}\text { Mean everolimus } \\
\text { concentration (ng/mL) }\end{array}$} & \multicolumn{5}{|l|}{ Month 12} \\
\hline & & \multicolumn{5}{|c|}{ Mean CsA concentration (ng/mL) } \\
\hline & & $<50$ & 50 to $<100$ & 100 to $<200$ & $\geq 200$ & All \\
\hline \multirow[t]{6}{*}{ Wound healing events } & $<3$ & $1 / 4(25.0)$ & $3 / 11(27.3)$ & $10 / 11(90.9)$ & $3 / 4(75.0)$ & $17 / 30(56.7)$ \\
\hline & $3-6$ & $1 / 4(25.0)$ & $8 / 98(8.2)$ & $27 / 80(33.8)$ & $22 / 29(75.9)$ & $58 / 211(27.5)$ \\
\hline & $6-8$ & $0 / 2(0.0)$ & $6 / 57(10.5)$ & 23/59 (39.0) & $10 / 22(45.5)$ & $39 / 140(27.9)$ \\
\hline & $8-12$ & $0 / 3(0.0)$ & $2 / 46(4.3)$ & $20 / 44(45.5)$ & $24 / 29(82.8)$ & $46 / 122(37.7)$ \\
\hline & $\geq 12$ & $0 / 0$ & $0 / 3(0.0)$ & $7 / 12(58.3)$ & $9 / 10(90.0)$ & $16 / 25(64.0)$ \\
\hline & All & $2 / 13(15.4)$ & 19/215 (8.8) & $87 / 206(42.2)$ & $68 / 94(72.3)$ & $176 / 528(33.3)$ \\
\hline \multirow{6}{*}{ Peripheral edema } & $<3$ & $4 / 6(66.7)$ & $4 / 10(40.0)$ & $6 / 8(75.0)$ & $4 / 5(80.0)$ & $18 / 29(62.1)$ \\
\hline & $3-6$ & $7 / 9(77.8)$ & $16 / 83(19.3)$ & $47 / 89(52.8)$ & $24 / 31(77.4)$ & $94 / 212(44.3)$ \\
\hline & $6-8$ & $0 / 3(0.0)$ & $9 / 51(17.6)$ & $26 / 46(56.5)$ & $22 / 30(73.3)$ & $57 / 130(43.8)$ \\
\hline & $8-12$ & $0 / 2(0.0)$ & $9 / 35(25.7)$ & $24 / 42(57.1)$ & $22 / 26(84.6)$ & $55 / 105(52.4)$ \\
\hline & $\geq 12$ & $0 / 0$ & $1 / 4(25.0)$ & $6 / 11(54.5)$ & 10/11 (90.9) & $17 / 26(65.4)$ \\
\hline & All & 11/20 (55.0) & $39 / 183(21.3)$ & 109/196 (55.6) & 82/103 (79.6) & $241 / 502(48.0)$ \\
\hline \multirow[t]{6}{*}{ Stomatitis/oral ulcers } & $<3$ & $0 / 3(0.0)$ & $0 / 9(0.0)$ & $0 / 2(0.0)$ & $0 / 3(0.0)$ & 0/17 (0) \\
\hline & $3-6$ & $0 / 3(0.0)$ & $1 / 119(0.8)$ & $8 / 85(9.4)$ & $5 / 18(27.8)$ & $14 / 225$ (6.2) \\
\hline & $6-8$ & $0 / 6(0.0)$ & $5 / 76(6.6)$ & $10 / 62(16.1)$ & $1 / 18(5.6)$ & $16 / 162(9.9)$ \\
\hline & $8-12$ & $0 / 3(0.0)$ & $1 / 65(1.5)$ & $7 / 40(17.5)$ & $2 / 13(15.4)$ & 10/121 (8.3) \\
\hline & $\geq 12$ & $0 / 0$ & $0 / 10(0.0)$ & $0 / 9(0.0)$ & $0 / 2(0.0)$ & $0 / 21(0)$ \\
\hline & All & $0 / 15(0)$ & $7 / 279(2.5)$ & 25/198 (12.6) & $8 / 54(14.8)$ & 40/546 (7.3) \\
\hline \multirow[t]{6}{*}{ New-onset diabetes mellitus } & $<3$ & $0 / 3(0.0)$ & $0 / 8(0.0)$ & $0 / 2(0.0)$ & $0 / 3(0.0)$ & $0 / 16(0)$ \\
\hline & $3-6$ & $1 / 3(33.3)$ & $2 / 125(1.6)$ & $10 / 85(11.8)$ & $3 / 14(21.4)$ & $16 / 227(7.0)$ \\
\hline & $6-8$ & $0 / 5(0.0)$ & $6 / 77(7.8)$ & $9 / 59(15.3)$ & $2 / 17(11.8)$ & $17 / 158(10.8)$ \\
\hline & $8-12$ & $0 / 3(0.0)$ & $0 / 57(0.0)$ & $10 / 42(23.8)$ & $5 / 14(35.7)$ & $15 / 116(12.9)$ \\
\hline & $\geq 12$ & $0 / 0$ & $0 / 9(0.0)$ & $1 / 10(10.0)$ & $4 / 6(66.7)$ & $5 / 25(20.0)$ \\
\hline & All & $1 / 14(7.1)$ & 8/ $276(2.9)$ & $30 / 198(15.2)$ & $14 / 54(25.9)$ & $53 / 542(9.8)$ \\
\hline \multirow[t]{6}{*}{ Hypercholesterolemia } & $<3$ & $1 / 4(25.0)$ & 15/18 (83.3) & 10/11 (90.9) & $7 / 10(70.0)$ & $33 / 43(76.7)$ \\
\hline & $3-6$ & $0 / 1(0.0)$ & $9 / 42(21.4)$ & $86 / 121(71.1)$ & $46 / 55(83.6)$ & $141 / 219(64.4)$ \\
\hline & $6-8$ & $0 / 3(0.0)$ & $7 / 27(25.9)$ & $47 / 67(70.1)$ & $32 / 38(84.2)$ & $86 / 135(63.7)$ \\
\hline & $8-12$ & $0 / 1(0.0)$ & $3 / 15(20.0)$ & $50 / 59(84.7)$ & $34 / 38(89.5)$ & $87 / 113(77.0)$ \\
\hline & $\geq 12$ & $0 / 0$ & $0 / 2(0.0)$ & $9 / 11(81.8)$ & $18 / 19(94.7)$ & $27 / 32(84.4)$ \\
\hline & All & $1 / 9(11.1)$ & $34 / 104(32.7)$ & 202/269 (75.1) & $137 / 160(85.6)$ & $374 / 542(69.0)$ \\
\hline \multirow[t]{6}{*}{ Hypertriglyceridemia } & $<3$ & $0 / 3(0.0)$ & $1 / 9(11.1)$ & $2 / 3(66.7)$ & $2 / 5(40.0)$ & $5 / 20(25.0)$ \\
\hline & $3-6$ & 0/2 (0.0) & $5 / 108(4.6)$ & $27 / 95(28.4)$ & $8 / 21(38.1)$ & 40/226 (17.7) \\
\hline & $6-8$ & $0 / 6(0.0)$ & $2 / 66(3.0)$ & $15 / 58(25.9)$ & $8 / 23(34.8)$ & $25 / 153(16.3)$ \\
\hline & $8-12$ & $0 / 4(0.0)$ & $2 / 55(3.6)$ & $15 / 46(32.6)$ & $10 / 17(58.8)$ & $27 / 122(22.1)$ \\
\hline & $\geq 12$ & $0 / 0$ & $0 / 10(0.0)$ & $4 / 11(36.4)$ & $4 / 6(66.7)$ & $8 / 27(29.6)$ \\
\hline & All & $0 / 15(0)$ & $10 / 248(4.0)$ & $63 / 213(29.6)$ & $32 / 72(44.4)$ & $105 / 548(19.2)$ \\
\hline \multirow[t]{6}{*}{ Low testosterone (males) } & $<3$ & $0 / 0$ & $0 / 2(0.0)$ & $0 / 0$ & 0/0 & $0 / 2(0)$ \\
\hline & $3-6$ & $0 / 2(0.0)$ & $13 / 68(19.1)$ & 13/39 (33.3) & $2 / 3(66.7)$ & $28 / 112(25.0)$ \\
\hline & $6-8$ & $0 / 4(0.0)$ & $13 / 44(29.5)$ & $7 / 26(26.9)$ & $2 / 7(28.6)$ & $22 / 81(27.2)$ \\
\hline & $8-12$ & $0 / 3(0.0)$ & $6 / 47(12.8)$ & $9 / 25(36.0)$ & $0 / 4(0.0)$ & $15 / 79(18.9)$ \\
\hline & $\geq 12$ & $0 / 0$ & $0 / 9(0.0)$ & $1 / 3(33.3)$ & $0 / 0$ & $1 / 12(8.3)$ \\
\hline & All & $0 / 9(0)$ & $32 / 170(18.8)$ & 30/93 (32.3) & $4 / 14(28.6)$ & $66 / 286(23.1)$ \\
\hline
\end{tabular}

The ability to assess the impact of CsA exposure based on this model was limited due to the nature of the study design, i.e., CsA exposure was highest in the early post-transplant period, when most acute rejection events occurred. Thus, as CsA exposure values were calculated up to the occurrence of an event, values would tend to be heavily skewed upward in patients with BPAR. Renal dysfunction and adverse events are less time-dependent than rejection, so renal and safety events showed the expected pattern of increasing inci- dences with rising CsA exposure (Table 3). Lastly, the study was not blinded due to the need to adjust everolimus and CsA exposure, and the analyses based on adverse event-reporting may reflect investigator bias.

In conclusion, we observed inferior efficacy in patients with low everolimus trough concentrations and an increased rate of wound healing, peripheral edema, and hypercholesterolemia at higher exposure levels. These findings are consistent with a relationship between everolimus 
exposure and efficacy and safety during the first two yr post-transplant in de novo kidney transplant patients receiving reduced CsA.

\section{Acknowledgements}

Study Investigators: Argentina: P Novoa, R Schiavelli, L Toselli; Australia: S Campbell, S Chadban, B Hutchinson, J Kanellis, P O'Connell, B Pussell, G Russ, R Walker; Brazil: D Carvalho, V Garcia, L Soares, H Tedesco Silva; Canada: M Walsh; Hong Kong: CS Li; Italy: A Albertazzi, M Carmellini, G Civati, G Colussi, F Schena; Korea: H Duck Jong, SJ Kim, YH Kim, YL Kim, YS Kim, IS Moon; New Zealand: H Pilmore; Slovakia: E Lackova, R Roland; Singapore: T Kee; South Africa: S Naicker; Sweden: G Tufveson; Taiwan: PH Lee; Turkey: E Akin, K Keven, A Uslu; United Kingdom: M Yacoob, H Riad, J Pattison; United States of America: S Abul-Ezz, E Alfrey, K Andreoni, M Aaronson, P Baliga, Y Becker, P Bolin, L Chan, DM Cibrik, M Cooper, A Cotterell, C Foster, C Franklin, S Jensik, TD Johnston, B Kahan, D Katz, D Kim, M Kumar, PC Kuo, J Leone, M Levy, B Marder, B Mistry, S Mulgaonkar, LL Mulloy, T O’Connor, PT Pham, K Rice, V Scantlebury, B Sankari, R Santella, H Shidban, F Shihab, D Slakey, RB Stevens, JR Thistlewaite, JD Welchel, CT Van Buren, N Youssef, C Zayas, G Zibari.

\section{Authors' contributions}

FSS, DC, LC, YSK, MC, RW, GZ, JP and HT-S recruited patients and collected study data. ZW provided biostatistical support. CCA contributed to the design of the current analyses. All authors contributed to the interpretation of the data, reviewed the manuscript critically, and approved the final version for submission.

\section{Funding}

The present study was funded by Novartis Pharma AG, Basel, Switzerland. A freelance medical writer prepared a first draft of the manuscript with funding from Novartis.

\section{References}

1. Schuler W, Sedrani R, Cottens S et al. SDZ RAD, a new ramekin derivative: pharmacologic properties in vitro and in vivo. Transplantation 1997: 64: 36.

2. Schuurman J-J, Cottens S, Fuchs S et al. SDZ RAD, a new rapamycin derivative: synergism with cyclosporine. Transplantation 1997: 64: 32.

3. Vitko $\mathrm{S}$, Tedesco $\mathrm{H}$, ERIS $\mathrm{J}$ et al. Everolimus with optimized cyclosporine dosing in renal transplant recipients: 6-month safety and efficacy results of two randomized studies. Am J Transplant 2004: 4: 626.

4. Chan L, Greenstein S, Hardy MA et al. Multicenter, randomized study of the use of everolimus with tacrolimus after renal transplantation demonstrates its effectiveness. Transplantation 2008: 85: 821.

5. Tedesco Silva H Jr, Cibrik D, Johnston T et al. Everolimus plus reduced-exposure CsA versus mycophenolic acid plus standard-exposure CsA in renal-transplant recipients. Am J Transplant 2010: 10: 1401.

6. Albano L, Berthoux F, Moal MC et al. RAD A2420 Study Group. Incidence of delayed graft function and wound healing complications after deceased-donor kidney transplantation is not affected by de novo everolimus. Transplantation 2009: 88: 69.

7. Ciancio G, Burke GW, Gaynor JJ et al. A randomized long-term trial of tacrolimus and sirolimus versus tacrolimus and mycophenolate mofetil versus cyclosporine (NEORAL) and sirolimus in renal transplantation. I. Drug interactions and rejection at one year. Transplantation 2004: 77: 244

8. Van Gurp E, Bustamante J, Franco A et al. Comparable renal function at 6 months with tacrolimus combined with fixed-dose sirolimus or MMF: results of a randomized multicenter trial in renal transplantation. $\mathbf{J}$ Transplant 2010: 2010: pii 731426.

9. Kovarik JM, Kaplan B, Tedesco Silva H et al. Exposure-response relationships for everolimus in de novo kidney transplantation: defining a therapeutic range. Transplantation 2002: 73: 920.

10. Lorber Mi, Ponticelli C, Whelchel J et al. Therapeutic drug monitoring for everolimus in kidney transplantation using 12-month exposure, efficacy, and safety data. Clin Transplant 2005: 19: 145.

11. Chan L, Hartmann E, Cibrik D, Cooper M, Shaw LM. Optimal everolimus concentration is associated with risk reduction for acute rejection in de novo renal transplant recipients. Transplantation 2010: 90: 31.

12. Poggio ED, Wang $X$, Weinstein DM et al. Assessing glomerular filtration rate by estimation equations in kidney transplant recipients. Am J Transplant 2006: 6: 100.

13. Nankivell BJ, Gruenewald SM, Allen R, Chapman JR. Predicting glomerular filtration rate after kidney transplantation. Transplantation 1995: 59: 1683.

14. Cockcroft DW, Gault MH. Prediction of creatinine clearance from serum creatinine. Nephron 1976: 16: 31.

15. Chou T, Talalay P. Quantitative analysis of dose-effect relationships: the combined effects of multiple drugs or enzyme inhibitors. Adv Enzyme Regul 1984: 22: 27.

16. Salvadori M, Scolari MP, Bertoni E et al. Everolimus with very low-exposure cyclosporine a in de novo kidney transplantation: a multicenter, randomized, controlled trial. Transplantation 2009: 88: 1194.

\section{Supporting Information}

Additional Supporting Information may be found in the online version of this article:

Table S1. Incidence of renal dysfunction parameters according to time-normalized cyclosporine (CsA) and everolimus (EVR) trough concentrations achieved to month 12 and month 24 (pharmacokinetic efficacy population). 